\title{
A SIMPLE METHOD OF PERCUTANEOUS CANNULATION OF THE PULMONARY ARTERY IN SMALL MAMMALS
}

\author{
J.B. Forrest, ${ }^{1}$ M.H. TODd,${ }^{2}$ AND D.J. CRAGG ${ }^{3}$
}

STUDIES OF PULMONARY HAEMODYNAMICS in living animals requires the insertion of balloontipped or triple-lumen catheters into the pulmonary artery for measurement of pulmonary artery and wedge pressures and of cardiac output by the indicator or thermodilution method. Small mammals such as the rabbit and guinea pig have been virtually excluded from such studies because correct placement of the se relatively stiff catheters is very difficult, time consuming and unpredictable. In our experience these lengthy manipulations are not well tolerated and result in an unacceptable high mortality rate. We have therefore devised a technique for pulmonary artery cannulation in small mammals which is easy and rapid and which is invariably successful in correct placement.

\section{METHOD}

An angled polypropylene introducer is used which is made from standard tubing $15 \mathrm{~cm}$ long, external diameter $3 \mathrm{~mm}$ and lumen diameter $2 \mathrm{~mm}$ (Figure 1). The distal $1.5 \mathrm{~cm}$ is heat angled at $90^{\circ}$ to the shaft and a marker made to indicate the direction of the angle. The proximal end has a tightly fitting silastic collar. The introducer is filled with heparinized saline and a No. 4 French gauge balloon-tipped Swan-Ganz flow-directed catheter (Edwards Lab. Inc.) is inserted so that the balloon tip lies just inside the distal end. The catheter is then filled with heparinized saline and connected to a transducer for pressure monitoring. Inflating the balloon fixes the position of the catheter tip with respect to the angled end.

The right jugular vein of an anaesthetized ani$\mathrm{mal}$ is exposed and the introducer-catheter assembly is inserted; this will now pass easily into

\footnotetext{
'J.B. Forrest, M.B., Ch.B., Ph.D., F.F.A.R.C.S., Associate Professor.

'M.H. Todd, B.Sc., Ph.D., Ontario Heart Research Fellow and Lecturer.

${ }^{3}$ D.J. Cragg, Technologist.

Departments of Anaesthesia and Medicine McMaster University Medical Centre, Hamilton, Ontario, Canada.
}

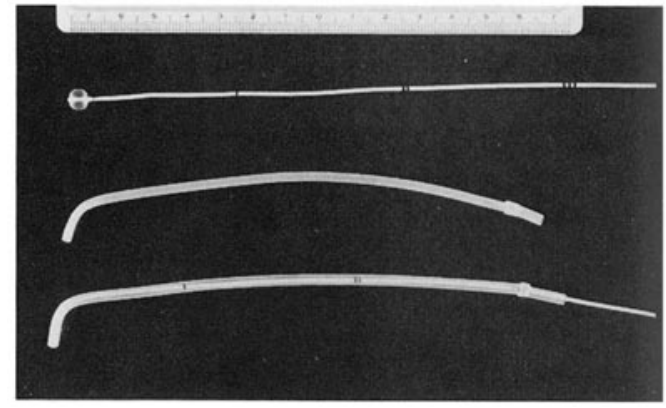

Figure 1. Photograph of the pulmonary artery catheter-introducer assembly. At the top is a centimetre scale and shown below are respectively (1) a balloon-tipped \# 4 French Swan-Ganz catheter, (2) the polypropylene introducer with the angled tip, and (3) a Swan-Ganz catheter inside an introducer.

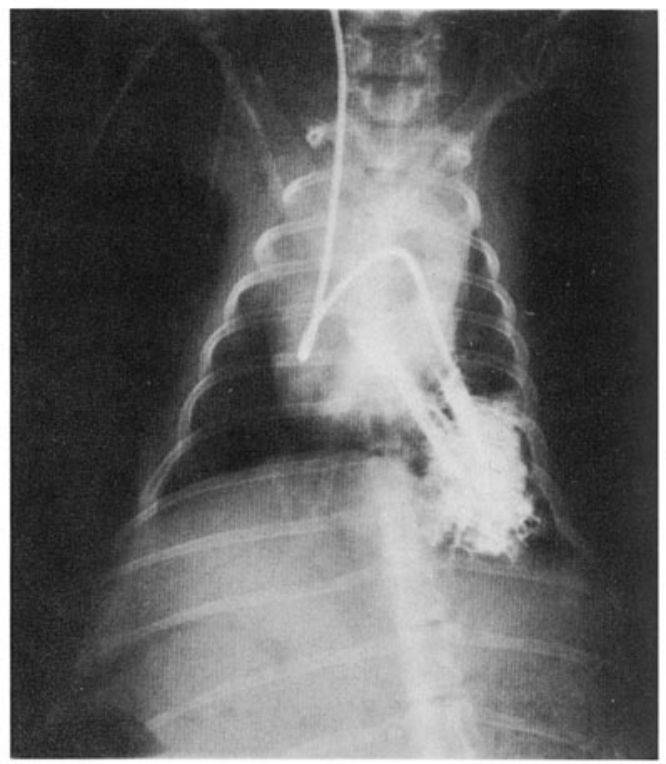

Figure 2. Chest radiograph of a rabbit showing a Swan-Ganz catheter in the left lower lobar branch of the pulmonary artery. Contrast media has been injected via the catheter to obtain an angiograph of the entire left lobar vasculature.

the right ventricle through the superior vena cava and the right atrium. Correct placement in the right ventricle is confirmed by the pressure signal and then the angled tip is rotated to point an- 
teriorly and slightly to the left and withdrawn until the angle impinges on the tricuspid valve. One $\mathrm{ml}$ of cold saline $\left(4^{\circ} \mathrm{C}\right)$ is flushed through the balloon-tipped catheter and the balloon is deflated; the catheter is advanced and will pass directly into the pulmonary artery. The use of cold saline stiffens the catheter within the introducer and thus creates the required bend on its distal end to enable it to enter the main pulmonary artery, which is confirmed by the change in the pressure signal. Inflation of the balloon will register the pulmonary wedge pressure. Once inserted the introducer can now be withdrawn, taking care to keep the balloon-tipped catheter in place.

Selective lobar artery cannulation is easily accomplished by advancing the Swan-Ganz catheter and gently rotating it to the left or to the right. Figure 2 is a radiograph of an adult rabbit showing a balloon-tipped catheter in the left lower lobar branch of the pulmonary artery and with the entire lobar vascular outlined by contrast medium.

\section{Discussion}

The main advantage of this technique for cannulation of the pulmonary artery in small animals is that, with very little experience, the whole procedure can be accomplished in a few minutes. Confirmation of placement does not require fluoroscopic control except for selective lobar cannulations, since the pressure signal is a reliable index. Operative procedures are virtually bloodless and small mammals tolerate these well. since manipulation of the catheter-introducer assembly is minimal. Since using this technique in over 200 experiments in adult rabbits we have found an absence of cardiac arrhythmias and further have reduced animal mortality rates to zero. Our experience, though less extensive in young rabbits, adult guinea pigs and rats is equally favourable. In these latter the procedure is only slightiy more time-consuming than in adult rabbits. The catheter size and introducer can be scaled down to reflect body size, but we have successfully used the larger assembly described above for placement of pulmonary artery catheters in rats for perfusion fixation of lungs within the intact chest. Additionally, we have used this procedure extensively for selective left lobar pulmonary embolism with autologous clot delivered through the Swan-Ganz catheter. In common with placement in larger mammals such as the dog, occasional movement of the catheter down the pulmonary artery or dislodgement into the right ventricle has occurred. Invariably this has resulted from unwinding of a loop of catheter within the ventricle during catheter manipulation. Once correct initial placement is achieved care should be taken not to manipulate the catheter unnecessarily. We have found it best to advance the catheter to the desired level within the pulmonary vasculature immediately after cold saline injection and then to fix its position with a ligature around the jugular vein. Should differential measurements be required at several levels, we suggest that before manipulation, withdrawal or advancement that a small amount of cold saline be injected to stiffen the catheter, just prior to repositioning.

In addition to measurement of pulmonary artery and wedge pressures this technique can be used for insertion of thermistor tipped triple lumen catheters for measurement of cardiac output by the thermodilution method. Further, sampling of blood through the pulmonary artery catheter for mixed venous blood gas and $\mathrm{pH}$ measurement is easily done.

This method of pulmonary artery cannulation thus opens up the possibility of detailed pulmonary haemodynamic studies in small mammals. Its use in neonates is a possibility, with development of appropriate sterilization procedures.

\section{SUMMARY}

A simple technique for catheterization of the pulmonary artery in small mammals is described. An angled polypropylene introducer is used to allow easy placement of Swan-Ganz and triple lumen thermistor tipped catheters for haemodynamic evaluation. Hitherto such information has been unavailable because of difficulties in placement of catheters as well as an unacceptably high mortality rate. In an extensive experience with this new technique no instances of cardiac arrhythmia or of death have so far been encountered.

\section{RÉSUMÉ}

La mise en place d'un cathéter de Swan-Ganz avec thermistor chez le petit animal (lapin, cobaye) est techniquement difficile et s'accompagne d'un taux de mortalité qui rend cette méthode inacceptable. Les auteurs ont imaginé un manchon fabriqué à partir d'un tube de poly- 
propylène coudé à la chaleur à son extrémité distale; un cathéter de Swan-Ganz de calibre 4 Fr y est glissé de façon à ce que le ballonnet seulement dépasse le manchon. Manchon et cathéter sont ensuite introduits dans une veine jugulaire (après dissection) et le cathétérisme de l'artère pulmonaire devient facile. Les auteurs ont beaucoup d'expérience avec la méthode et ne rapportent pas d'arythmies ou de morts chez les animaux ainsi appareillés.

\section{ACKNOWLEDGEMENTS}

This work is supported by grants from the Medical Research Council, Grant Nos. MA 5880 and MA 5811, and from the Ontario Heart Foundation, Grant No. OHF 15-19. 